\title{
Para-Sights: Multiplied Perspectives on Surveillance Research in Art Educational Spaces.*
}

\author{
Robert W. Sweeny'
}

\begin{abstract}
In this paper the author outlines multiple approaches regarding surveillance research in the visual arts and art education. The notion of the parasite is used to diagram power relationships that are addressed by visual artists and activists engaged with the mechanisms of both surveillance and dataveillance. These parasitic practices are then compared with actions from art educational spaces, allowing for the surveillance that is inherent to pedagogy to be analyzed and critiqued.
\end{abstract}

\section{Beyond Sight}

I have lived the past four years of my life becoming increasingly aware of eyes: the eyes that I use to watch, and the eyes that watch me, the mechanical lenses that mimic these biological processors, intertwining to create complex networks of seeing and being seen. As a result, the intersections between power and vision have become central to my research and my teaching. These are intersections that are particularly relevant when discussing such practices within the context of the visual arts, as the related ways of seeing are inherently self-reflexive. ${ }^{2}$

In this process of self-reflection - looking at how I see works of art, how I see others look at works of art, how they see me, etc. - I have become suspicious, although not necessarily suspicious of others. Rather, I have become suspicious of my own practices. Actively engaging with these networks of vision, questioning the relationship between my practices as an art educator and contemporary forms of surveillance, I have become entwined with these mechanisms, sometimes magnifying their capabilities, sometimes rendering them useless, though never to the point of meaninglessness.

\footnotetext{
* An early version of this paper was presented at Version 5: Invincible Desire, Chicago IL, April 27-May 1,2005 . I wish to extend special thanks to the organizers of this event for this opportunity.

1 Indiana University of Pennsylvania, Indiana, USA. mailto:

2 Many artists have explored and exploited this self-reflexivity, creating work that implicates the viewer as participant in the creation of meaning. Marcel Duchamp stands as a primary example, questioning the role that vision plays in the reception of his own work. As he said, in regards to the visual arts: "One can look at seeing. Can one hear hearing, feel breathing, etc?” (Duchamp, 1989)
} 
In my work as an art educator I am primarily concerned with meaning. The meaning of images, how individuals construct meaning of a visual nature, whether this process is socially determined, institutionally prescribed, and/or individually guided. As a result of my current research dealing with the relationship between surveillance technologies and theories and the visual arts, I have become increasingly aware of the ways in which artistic practices feed into the various forms of surveillance that continue to proliferate in contemporary social life. Do the visual arts contribute to this proliferation, fetishizing the gaze? If so, what options do art educators have in trying to address these issues without appearing paranoid?

Paranoia might be an understandable outgrowth of the multiple manifestations of contemporary surveillance technologies. While it is certainly a valid response, it is, as Lyon (1994) illustrates, one that is limited, both intellectually and politically. Therefore, it might be more relevant for those dealing with expanding surveillance (and dataveillance) networks to look not beyond mind (as the Latin etymology implies), to not lose the ability to engage intellectually with the technologies, but instead to those aspects of vision that lie beyond the range of human perception: to the paravisual, or, perhaps, para-sight.

Contemporary surveillance technologies increasingly operate in the spaces beyond sight. Cameras see beyond the limits of the human eye, networked technologies share information faster than the mouth can speak, contemporary computers process quantities of data far beyond the capabilities of the human brain. Those involved with the visual arts might learn much from studies regarding current surveillance technologies, going beyond the boundaries of traditional research methodologies, informing practices that interrogate the dynamics of power and vision in art educational settings.

This has been the emphasis of my research for the past four years. In order to share my findings, I will briefly describe a few projects with which I have been engaged. While they are varied, they each can be connected through their emphasis on the analysis of power and vision in art educational settings, where, typically, imbalances in both are identified and questioned. These imbalances will be described through the use of a biological model: the parasite. ${ }^{3}$

\section{Parasitic Exchanges}

Surveillance is an inherent aspect of human social behavior, contributing to the exchanges that extend beyond the self, creating formations of groups, families and communities. The surveillance that binds individuals within these social structures are necessary for a general sense of order; yet, when the architecture of surveillance technologies expands beyond the ability for individuals to take part in the exchange of information, when the possibility for feedback is eliminated, the balance shifts, placing the health of the system in jeopardy.

3 The parasite has been used variously in fields far removed from biology: As a metaphor for social interactions and the welfare state (Zimmer, 2004); As a literary device (Doyle, 1894); In film theory (Shaviro, 2003); As a model for architectural interaction (Lynn, 2003); As a diagram for Complexity and Information Theory (Serres, 1982). 
It is necessary to look at forms of social interaction that restore balance to unequal power relationships, to look to both microscopic and micropolitical situations: to look to the parasite. In nature, parasites exist in a variety of forms. Typically, they exist through external attachments to or by infiltrating the body of a host organism. Once involved within the system, the parasite draws energy from its host, always maintaining a balance, never taking too much, as this might run the risk of depleting its source. ${ }^{4}$

In my early research at The Pennsylvania State University (Sweeny, 2004a), I compared this biological model to the organization of educational systems primarily located in the United States, as well as artists who exploit and critique power relationships using networked technologies such as the Internet and surveillance camera systems. I developed the idea that a school might be thought of as a complex system that functions best when information exchange is just beyond homeostasis, yet maintains a balance (Sweeny, 2004a). ${ }^{5}$ This balance is maintained through networks of exchange, where individuals in the school share power, and relationships are constantly negotiated through forms of feedback that allows the system to adapt and change. 'Unhealthy' schools are those that limit the possibilities for feedback, where, instead of power being shared, it is maintained by authoritative rule, only to be undermined through subversive student acts beyond the sight of those in power. ${ }^{6}$

A parasitic model of exchange might best describe the variety of interactions that occur between the educator and student within such 'unhealthy' spaces. In architectural terms, architect and theorist Lynn (1998) suggests that there is no unity that preexists the parasite/host relationship. There is always an imbalance of power, and always many layers of power functioning simultaneously within these spaces. Parasites can become hosts to other parasites, just as students draw power/knowledge from teachers, and each other, with the possibility for teachers to draw from students. ${ }^{7}$

The challenge for educators in general, and art educators specifically, is to acknowledge how these tangled power relationships in the classroom find their form in networks of visuality, and learn from similar types of interaction existing elsewhere. What happens outside of the centralized view of the teacher? If students are using the language of the visual arts to double-code messages of critique, can they become integrated into the fabric of the class, or would this sap their power?

I have suggested elsewhere that educators can learn much from the work of collectives

\footnotetext{
4 For an entertaining discussion of the operations of biological parasitism, see Zimmer (2004)

5 Byrd (2003) presents a compelling discussion of homeostatic activity as related to evolution, in Chaos and Life: Complexity and Order in Evolution and Thought. In terms of networks and descriptions of life, Richard Doyle presents a provocative reading of homeostasis and balance in Wetwares: Experiments in Postvital Living (2004).

6 An interesting parallel can be drawn between this notion of the 'unhealthy' school and the 'No Child Left Behind Act of 2003,' which states that schools that do not meet standardized test scores for three years can be deemed 'failing' and turned over to private contractors who will then manage the school: The feedback from the standardized test resulting in a tightly managed system that allows for even fewer forms of feedback. For a discussion of resistance to NCLB, see Winerip (2005).

7 As an aside, I have found that, when teaching digital technologies in the classroom, students are typically better informed about the potential applications found therein, reversing the flow of knowledge, host becoming parasite.
} 
such as the Institute for Applied Autonomy and The Surveillance Camera Players, along with the work of Steve Mann, who engage in tactical forms of critique taking place within the gaze of surveillance systems. ${ }^{8}$ I will now turn to a discussion of examples from my teaching informed by the notion of the parasite, in order to further explore the networks of vision and power that operate within my practices.

\section{Sighting noise in the art museum}

After the completion of this work, my research interests turned to the specifics of embodiment as enacted by individuals in areas of surveillance; in particular, those related to the visual arts. One specific work created at the time allowed me to see how students were exploring the panopticism of museum spaces as it related to their own lives. A video piece created by students in Art 100: Introduction to Art, a course I taught in Fall 2002 at The Pennsylvania State University, dealt with the complex issues related to surveillance and power as related to art institutions.

The students that created this piece were asked to construct a project that related to the effects that digital technologies have had within their lives. Using the Palmer Museum of Art - located on the Penn State University Park Campus - as host, they begin to explore the various positions that make up the networks of surveillance within this institutional space. They were provided with a variety of technologies - tape recorder, video camera, still digital camera - and were asked to explore the possibilities for self-referentiality provided by the technologies. They were to play with the reflexivity related to seeing and being seen, to critique the technologies that were used in the process. ${ }^{9}$

These students chose the museum as a space that is based in looking and the 'male gaze', influenced by our readings of the course text: Ways of Seeing (Berger, 1972). Doubling the gaze of the surveillance camera through handheld video, then recording the individual recording the camera, they created a layered experience that lead to confusion. Through a tight editing process, they constantly reminded the viewer of the position of the camera operator (and the apparent laxness of the security guard) through the rapidly shifting camera shots. The images begin to break up as filmed image was filmed, layered with music that approached noise, only to return to a calm denouement, backing out of the doors that introduced the walking protagonist into a panoptic hall of mirrors.

This video deals with the specificities of this museum on campus, although it makes connections to the dynamics of seeing reinforced by museums and the objects on display. This is a space that depends upon the power of the host, primarily identified through the ability to display work in a controlled environment. Their parasitic actions allow for ways of seeing that exist outside of those framed by the structure of the museum. Drawing from

8 Sweeny (2003) describes the relationship between the SCP and pedagogy. In this paper I use the term tactic, borrowed from Michel de Certeau, who describes the potential for unrecognized forms of critique within capitalist systems, in The Practice of Everyday Life (1984). The tactic is most interesting in regards to surveillance studies, as it might draw together numerous approaches use to engage with, deflect, or disrupt such technologies. In a similar manner, Gary Marx has outlined a number of these approaches (Marx, 2003).

${ }^{9}$ Images from this video will be made available at http://www.untwine.net 
the surveillance feed, their multiple channel video identified the presence of the unmarked cameras in the space, in a manner similar to the walking tours offered by the Surveillance Camera Players, although their work is closer to music video than street theatre. ${ }^{10}$ Multiplying the ways of seeing that are reinforced in the museum, this video reminds us of the disruptions that are a part of public spaces. It reminds us of the responses that the museum makes an attempt to suppress, through neutral colors, padded surfaces, wall tags, and surveillance cameras.

The web-based project Eyes of Laura raises similar questions regarding the power of the gaze in the museum, in this case the exterior public areas surrounding the Vancouver Museum of Art in Vancouver, BC, Canada. The website allows viewers to read the weblog of 'Laura' - described as a guard at the gallery - and access surveillance cameras placed on the outside of the gallery. ${ }^{11}$ This project adds a sense of personal reflection to the impersonal images of surveillance, allowing the viewer to question not only the weblinked images on the computer screen, but the identity of 'Laura,' and 'her' intent in making the images available online.

These projects force me to reflect upon my position in the classroom, and how many art classrooms rely upon and reinforce the control inherent in exhibiting works of art. They allow me to question the panopticism of the masterpiece and the power that the museum structure reinforces. This piece forces me to acknowledge my position behind the camera, outside of the surveillance of my pedagogy, and inspires me to look for moments of incongruity, of noise within my often stale, rudimentary educational compositions.

Serres (1982) presents a rhizomatic analysis of noise as related to communication and complexity theory in The Parasite. This dense narrative is based on his native French interpretation of 'parasite,' which can be defined through the biological examples used in this paper, but also as dinner guest, and noise. Shifting between these three meanings, Serres develops the idea that the parasite can be thought of as an uninvited guest who exchanges conversation for food, ideas for objects. The parasite as noise introduces chaos into stable existing systems, resulting in a state of increased complexity.

This interpretation of noise relates to the structure of cybernetic systems that rely upon various forms of communication to unify disparate elements. Can the examples discussed earlier be seen as an example of noise, introduced within stable institutional systems? Does the museum video alter the way individuals see (and are seen in) that space, if only temporarily? Does the Eyes of Laura site destabilize the security of the Vancouver Art Gallery? Do these projects add noise to their specific visual fields, allowing for new ways of seeing?

One point should be made clear: the noise created through tactical exchange with surveillance technologies surely depends upon the position of the participant. The surveillance video made by Art 100 students was created for a class project, accompanied by all of the associated institutional requirements and responsibilities. The students had asked permission of the security guard and me. Eyes of Laura puts the viewer in the position of the museum guard, allowing for the position of power to be analyzed, and

10 See: Sweeny (2003) for further information.

11 Site available at: http://www.eyesoflaura.org/ 
perhaps reinforced by the viewer. These events might therefore be seen as facile gestures lacking critical potential, neutralized by their specific institutional frameworks. I would argue that, while this might be the case, each person engaging with these technologies walks away from the experience with a new view on surveillance, an increased awareness of not only the eyes that watch and are watched, but creative ways to engage with these networks of vision, creating noise that might disrupt the power of the surveillance camera, or, perhaps reinforce its gaze.

If seen in this light, the relationship between noise and communication, between host and parasite, is always present. There is no music without noise, just as there is no organism that exists without interaction with another. Individuals have the ability to engage with these technologies, and to shift power flows through even the subtlest of actions. However, the relationship between host and parasite is often complex. In nature, parasites often require the use of intermediate hosts in order to reach their target. A parasite for a host can easily become a host for another parasite, only to begin the cycle again. The same might be said for noise, as well; producing and distributing sound through a medium changes the sound. The mediation of images through video technology changes the meaning of the image, as the video piece illustrates. Filming the subject in the museum, then cutting to a shot of the subject being filmed by surveillance camera acknowledges the multiple gazes active in the museum space, and how different positions might be acknowledged. These intermediary channels should be acknowledged as participants in the creation of meaning; the surveillance camera can process only so much information, resulting in a loss of image clarity, and a reduction of subjectivity to binary constraints: still/moving, black/white, good/bad. ${ }^{12}$

The possibilities for parasitic noise as a critical act lies in its ability to blur these boundaries, to complicate simplistic binaries. Noise as critical act must draw energy from the mechanisms of surveillance, and in doing so it relies upon the power of the host. It must use the resources available to it, turning them against their producer. Not to reinforce modernist binaries, destroying the power source only to become the power source. The ability to multiply meanings, to overcode the system and actively participate within complex technological and visual networks is contained in the operations of the parasite.

\section{Sights of cyborgs and databodies}

Folding these experiences back into my practice, I set out to directly address the relationship between surveillance and education. I was given the opportunity to revisit my earlier activities at the 2004 New Forms Festival in Vancouver, BC, Canada, where I presented a performance piece that magnified these issues through an absurd lens. I prepared a 'sales pitch' for a new device that would allow educators to monitor all classroom behaviors through a head mounted device that fused pedagogue and camera: the pedagopticon:

12 Fiske (1999) discusses the tendency for surveillance technologies to reinforce racial biases, based on the ability for most surveillance cameras to only see the most basic of features: i.e.: skin color. 


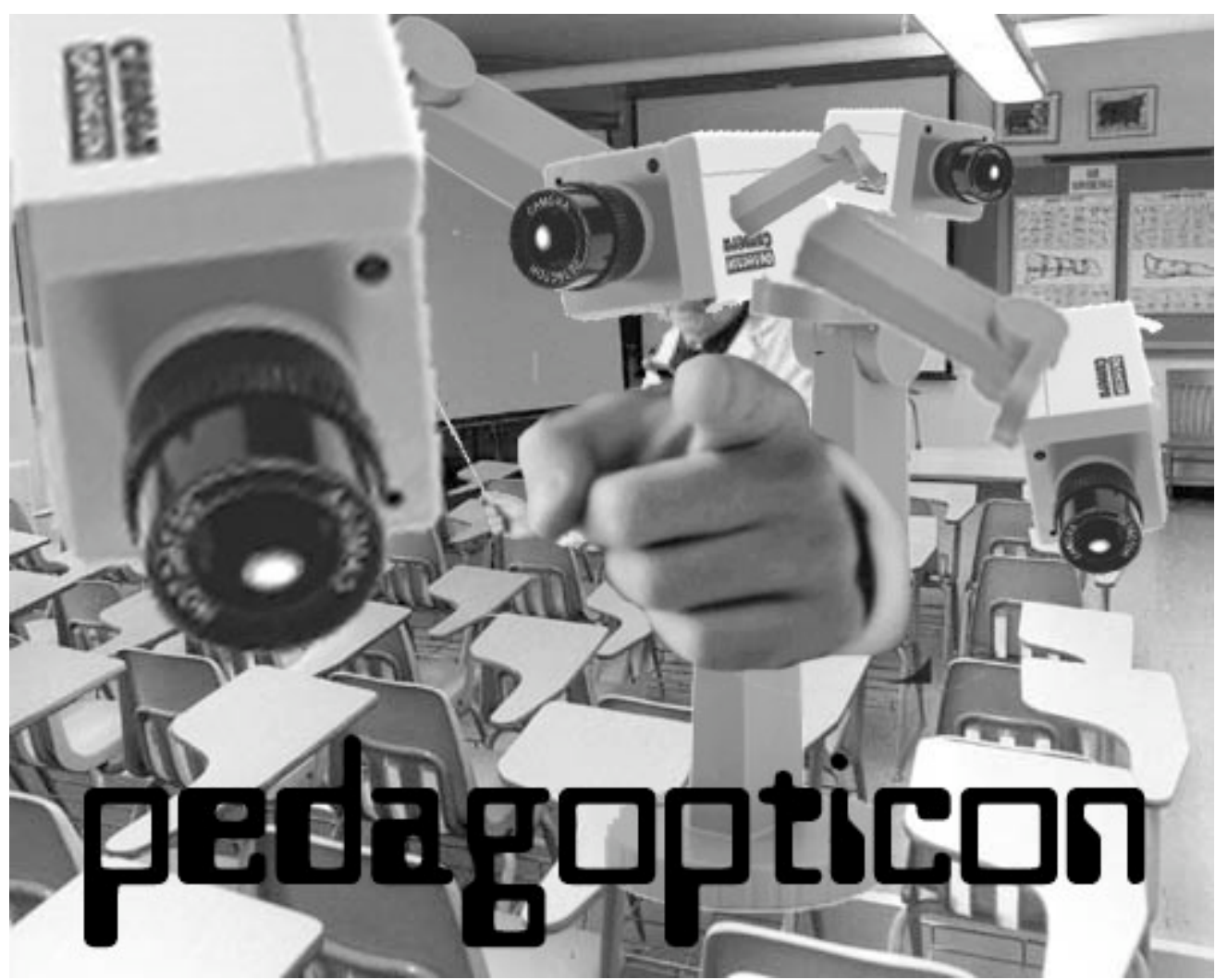

Figure 1: Pedagopticon, 2004 (courtesy of author).

Welcome, Ladies and Gentlemen, to the future. The future of technology, of education, of sight. What you will see today is the very latest in developing technology, a device that borrows from the past in order to act upon the future, before it happens. The "Pedagopticon". The Pedawhat, you may ask? The "Pedagopticon"! Part pedagogue, part Panopticon. The very latest in cyborg pedagogy, the "Pedagopticon" fuses the control that is inherent to teaching with cutting edge optical equipment, creating situations in which participation is guaranteed, disruptions are a thing of the past, and students are efficiently yet gently coerced into learning (Sweeny, 2004b).

The pedagopticon project allowed me to return to an analysis of my position in the classroom. ${ }^{13}$ In my research for the project I explored the relationship between control and education in the United States, drawing primarily from the work of educational historian Spring (2001). In The American School 1642-2000, Spring discusses the importance of uniformity within public school classrooms in the early portion of the $20^{\text {th }}$ century. Beginning with desks placed in grid formations that were bolted to the floor, many educators sought to control student movement and behavior as much as possible. In contrast to the beliefs of progressive educators such as John Dewey, influential educational psychologists William James and Edward Thorndike advocated for regimentation and teacher-led order in school activities. These regimented activities were

13 Documented at http://www.angelfire.com/electronic2/technologyisthedevil/pedagopticon The full paper is available at http://www.untwine.net 
widely promoted by Bagley (1925) in Classroom Management, a text that was reprinted thirty times in the U.S. between 1907 and 1927, influencing many contemporary educators (Spring, 2001).

This regimentation led to the implementation of the management theories of behaviorist Skinner (2003), who proposed that schools could be scientifically engineered to function optimally through reinforcements - both positive and negative - from management: i.e., teachers. He also suggested that educators borrow from developments in early cybernetic research. Skinner suggested that educators borrow from computer science, utilizing the new technologies known as 'teaching machines':

Based on the principles of behaviorism, teaching machines were to instruct by presenting students with small units of knowledge and providing constant reinforcement. By the late 1970's and 1980's, the original principles underlying the teaching machine were incorporated into many educational software programs for the microcomputer (Spring, 2001, p. 427).

Though presented as an antidote to a passive model of learning, Skinner's concept of the 'teaching machine' was limited by the technologies of the period. Computers were thought of as stand-alone machines, not the components of complex electromechanical networks common today. What was thought of as highly personalized instruction was inevitably reduced to programmatic behavior.

In the pedagopticon project I became the machine, and in doing so highlighted the aspects of pedagogy that are based in visual forms of control. In using fairly accessible technologies (inexpensive webcams, laptop) I augmented their intended use. I added to their meaning, drawing connections between biological and technological networks of vision in the classroom. This project was influenced by my own experiences with digital technologies in the art classroom, as well as the writings of art educators Garoian and Gaudelius (2001), who proposed the notion of a 'cyborg pedagogy' that draws from performance art theory to critique the relationship between art educators and developing technologies. $^{14}$

While educational spaces have always been infused with various technologies, and monitored through a variety of methods, recent events such as the placement of surveillance cameras in every classroom in Biloxi, Mississippi have raised questions concerning the civil liberties of students, teachers, and staff alike (CNN, 2003). The notion of surveillance as simply the collection of visual information is rather limiting, in fact. As Lyon (1994) discusses, global digital networks have created situations in which data are easily collected, distributed, and interpreted. This collection of data acts as a method of surveillance that is subtle and increasingly pervasive, as individual behavior is

\footnotetext{
14 One performance artist that they draw from is Stelarc, who has consistently addressed the boundaries between human and machine through provocative performance pieces. One such piece, titled (appropriately enough) Parasite (1993), places his body within mechanical, electrical, and digital networks, allowing distant participants to control his body. Stelarc believes that, in a reversal of the power relationship that finds humans in control of digital machines, that humans are, in fact so dependent in this relationship that they are parasites, relying upon the machinic host.
} 
monitored through the gathering information on consumer transactions and personal health records, resulting in what has described as a databody. ${ }^{15}$

Artist Julia Scher has, since the mid-1990's, explored the relationship between cyberspace, surveillance, and identity. Her projects demonstrate the increasing relevance of dataveillance, as computer systems become networked and are able to share data concerning individuals. Her 1996 project Securityland, hosted by the Walker Art Center in Minneapolis, MN, deftly fuses aspects of traditional forms of surveillance with approaches of collecting data that complicates the relationship between the participant and her/his databody. ${ }^{16}$ As a project that is entirely online, the Securityland project utilizes the hypertextual structure of the Internet to provide links both within the site and to related exterior links. It clearly addresses the contemporary fears regarding digital identity, either augmented through online purchases or identity theft. She also addresses the gaze associated with digital technology, with many pages featuring a surveillance camera lens aimed directly at the viewer.

The ability for information to circulate on the Internet without the consent of the user leads to new potential for individual monitoring, but it also provides the user with the flexibility to generate false data, subverting the process of data collection and identification. The questionnaires that appear within Securityland point to the notion that online identity is fluid; race, gender, and sexuality are easily morphed. As Turkle (1996) has shown, the ability for individuals to modify identity is a visible manifestation of the notion of fragmentation that has accompanied a shift to a postmodernist era. The ability for an individual to assume any number of identities in online interaction seems to counteract the potential for surveillance technologies to normalize behavior, to force individuals into binary positions as previously discussed.

The creation of databodies is also closely tied to educational practices. Taking attendance, marking grades, and filling in seating charts are all forms of data collecting is used to monitor student behavior. The direct use of digital technologies that collect data is just beginning, however. The Sutter CA school district was recently ended their trial run that required students to wear ID cards enabled with RFID (radio frequency identification) technology, after challenges from parents backed by the ACLU (Zetter, 2004). The refusal of this potentially invasive technology is promising. However, if educators are to learn from this event, we should investigate the general impulse to catalog and control that is reinforced in many schools, which has lead to what Deleuze (1992) described as "The Societies of Control."

Educators and researchers should also look to student tactics designed to override and overcode these systems; the changing of grades on report cards, forging excuses, and cheating on tests that only has the potential to multiply in a network society (Castells, 1996) The creation of databodies intended to confuse and critique, and the extension of the student body through cyborg augmentation, stand as possibilities for the issues regarding vision and power in educational spaces to be discussed, and for parasitic

15 For an overview of databodies and artistic practices related to the work of Critical Art Ensemble, among others, see http://worldinformation.org/wio/infostructure/100437611761/100438659649?opmode=contents Accessed 8/05. ${ }^{16}$ Available online at http://adaweb.walkerart.org/project/secure/corridor/sec1.html. Accessed 8/05 
exchange to be acknowledged.

\section{Insights}

Going beyond the boundaries of sight - adding noise to images of control, adding technological lenses to the body of the educator - have allowed me to see my work as art educator anew. As I have shown with the previous examples, it is important to analyze both the technological gadgetry of surveillance and dataveillance as well as the individualized actions that reinforce, repurpose, or resist these mechanisms. Many artists, activists, and collectives are currently forming responses that work along similar lines, addressing the power of the gaze in museum spaces and through the creation of cyborg entities and databodies. Researchers dealing with these issues would be well served by acknowledging the work of groups such as the Surveillance Camera Players, the creator(s) of the Eyes of Laura website, and Julia Scher, as they each point towards possibilities for creative, critical interaction and intervention within the societies of control.

The complexities of human sight, of seeing and being seen, make the study of surveillance all the more relevant in art education. If art educators who are confronted with increasingly sophisticated forms of technology do not inquire as to the possibility for their critical application, we allow these technologies to reinforce inequities, potentially destabilizing the relationship between parasite and host, becoming viral. By acknowledging the complex networks of vision that run through art classrooms and museums, and the body modifications represented by the cyborg and the databody, art educators might then form tactics that resist the normalization associated with the technologies of surveillance, resonating as parasitic critique within the educational (host) body.

\section{References}

Berger, J. (1972) Ways of seeing. New York: Penguin.

Byrd, R. (2003) Chaos and life: Complexity and Order in Evolution and Thought. New York: Columbia University Press.

Castells, M (1996) The rise of the network society. Oxford, UK: Blackwell.

CNN. (2003) School district installs cameras in every class, hall. 13 August. Available online at http://edition.cnn.com/2003/EDUCATION/08/12/classroomcameras.asp/ [Accessed 11/05]

De Certeau, M. (1984) The practice of everyday life. (Trans. Steven Rendall). Berkely, CA: California.

Deleuze, G. (1993) Postscript on the societies of control. October 59, Winter 1992: 3-7.

Doyle, A.C. (1894) The Parasite. New York, NY. Harper Brothers.

Doyle, R. (2003) Wetwares: Experiments in Postvital Living. Minnesota: University of Minnesota Press.

Duchamp, M. (1989) The Writings of Marcel Duchamp. (M. Sanouillet and E. Peterson, eds.) New York; Da Capo Press. 
Fiske, J. (1998) Videotech. In The Visual Culture Reader (N. Mirzoeff, ed.) New York: Routledge, pp.153162.

Foucault, M. (1977) Discipline and Punish: the Birth of the Prison. (A. Sheridan, trans.). New York: Random House.

Garoian, C. and Gaudelius, Y. (2001) Cyborg pedagogy: Performing resistance in the digital age. Studies in Art Education 42(4): 333-347.

Lynn, G. (1998) Body matters. In Greg Lynn: Folds, blobs, and bodies: Collected essays. Bruxelles, Belgium: Books-by-Architects.

Marx, G (2003) A Tack in the Shoe: Neutralizing and resisting the new surveillance. Available at http://web.mit.edu/gtmarx/www/tack.html [Accessed 08/05]

Serres, M. (1982) The Parasite (L. Schehr, trans.) Baltimore, MD. The Johns Hopkins Press.

Shaviro, S. (2003). Connected, or How to Live in a Network Society. Minneapolis, MN. University of Minnesota Press.

Skinner, B.F. (2003) The Technology of Teaching. Cambridge, MA: B.F. Skinner Foundation [originally published 1968].

Sweeny, R. (2003) Between devil and detournement: Embodied acts as methods of critical inquiry in educational spaces. Surveillance \& Society 1(4): Available online at http://www.surveillanceand-society.org/articles1(4)/detournement.pdf

Sweeny, R. (2004a) _net_work_ed: Simulated bodies and objects intertwined in cyberplaces and art educational spaces - threads of a critical digital pedagogy. Unpublished dissertation. The Pennsylvania State University.

Sweeny, R. (2004b) The pedagopticon: Beyond 'discipline and punish' in the classroom. Presentation at 2004 New Forms Festival, Vancouver, BC, Canada.

Turkle, S. (1996) Life on the screen: Identity in the Age of the Internet. New York. Simon and Schuster.

Winerip, M. (2005) Holdouts against standard tests are under attack in New York. New York Times. Available at: http://www.nytimes.com/2005/06/15/education/15/education.html [Accessed 06/05]

Zetter, K. (2004) School RFID plan gets an F. Wired Online. Available at: http://www.wired.com/news/privacy/0,1848,66554,00.html [Accessed 06/05]

Zimmer, C. (2004) Parasite Rex: Inside the Bizarre World of Nature's Most Dangerous Creatures. New York: Free Press. 